\title{
Asthma and Air Pollution. Where are We?
}

\author{
Bénédicte Jacquemin ${ }^{1}$ and Jordi Sunyer ${ }^{2}$
}

${ }^{1}$ UMR-S 1168, VIMA: Ageing and chronic diseases. Epidemiological and public health approaches, INSERM, Villejuif, France; UMR-S 1168, Université Versailles Saint Quentin, France; Centre for Research in Environmental Epidemiology (CREAL), Barcelona, Spain; Universitat Pompeu Fabra (UPF), Barcelona, Spain; CIBER Epidemiología y Salud Pública (CIBERESP), Barcelona, Spain; ${ }^{2}$ Centre for Research in Environmental Epidemiology (CREAL), Barcelona, Spain; IMIM (Hospital del Mar Medical Research Institute), Barcelona, Spain; Universitat Pompeu Fabra (UPF), Barcelona, Spain; CIBER Epidemiología y Salud Pública (CIBERESP), Barcelona, Spain

\section{ABSTRACT}

Asthma incidence and prevalence have increased in the last decades, suggesting a role of environmental factors including air pollution. In this manuscript, we summarize the evidence of the role of air pollution on (i) asthma exacerbations, (ii) asthma incidence in children, and (iii) asthma incidence in adults, pointing out the most important publications in each of these three areas. There is solid evidence that air pollution causes asthma exacerbations, characterized by hospital admissions, emergency department or doctor's visits, medication intake, or absenteeism. The evidence regarding the effect of long-term air pollution exposure on asthma onset is also quite robust. In children, many studies have associated air pollution or proximity to traffic with asthma incidence, and while there are some negative publications, the evidence for an association is appealing. In adults, several studies also point to a positive association between air pollution and asthma incidence. Furthermore, there is a lot of knowledge about the mechanisms of the different agents involved. Gases, that are oxidants, could be more associated with acute manifestations of the disease and particles, more related with chronic inflammation, could be more associated with incidence. Diesel particles have been associated with both exacerbations and incidence. However, research is still needed to better understand and identify the underlying mechanisms related to the specific pollutants and specific sources. More research is also needed to identify more susceptible groups such as males, non-smokers, or persons with another chronic condition such as atopy or obesity. (BRN Rev. 2015;1:78-91) Corresponding author: Bénédicte Jacquemin, bjacquemin@creal.cat

Key words: Air pollution. Asthma exacerbations. Asthma incidence.

\section{Correspondence:}

Bénédicte Jacquemin

CREAL-Centre for Research in Environmental Epidemiology

Parc de Recerca Biomèdica de Barcelona

Doctor Aiguader, 88

08003 Barcelona, Spain

E-mail: bjacquemin@creal.cat

Date of reception: 07-07-2015

Date of acceptance: 04-08-2015

DOI: 10.23866/BRNRev:2015-M0008 


\section{INTRODUCTION}

Asthma incidence and prevalence have increased in the last decades, affecting between $5-10 \%$ of the population ${ }^{1}$. In 2010, asthma ranked as the 28th leading cause of disability adjusted life-years worldwide ${ }^{2}$. Asthma is a heterogeneous disease that appears more frequently in childhood, but can also appear in adulthood. Asthma is a particularly complex disease than can persist, remit, or show a variable disease activity over time ${ }^{3,4}$. Its increase in the last decades strongly suggests a role of environmental factors, which certainly play a role as acute triggers of attacks, but probably also as causative agents.

Research on environmental factors associated with asthma incidence or exacerbations is very extensive. In the 1980s, the first hypotheses explaining the incidence increase pointed to allergen exposure (or non-exposure), tobacco, and air pollution ${ }^{5}$. Outdoor air pollution is a complex and variable mixture of multiple pollutants. Transport, power generation, industrial activity, and biomass burning are the predominant anthropogenic sources. The mix of outdoor pollutants varies over space and time, reflecting the diversity of sources as well as the effect of atmospheric processes. Outdoor air pollution has evolved in the last decades. In Europe and North America, air pollution related to industrial effluents is better controlled, and episodes of severe air pollution related to industrial activity have mostly disappeared. Currently, the main source of air pollution in Europe and North America is vehicular traffic, and the air pollutants of major interest in urban areas are those related to traffic: nitrogen dioxide $\left(\mathrm{NO}_{2}\right)$ and particulate matter (PM), or ozone $\left(\mathrm{O}_{3}\right)$ which is a by-product of $\mathrm{NO}_{2}$.
With the decrease of air pollution levels in the 1980s, associated with a better control of industrial emissions and residential coal combustion, interest in air pollution research decreased as it was thought that air pollution levels were too low to be associated with health problems ${ }^{6}$. However, at the beginning of the 1990s, the Barcelona group found that air pollution levels below the air quality recommendations had an effect on respiratory health, namely on chronic obstructive pulmonary disease (COPD) exacerbations ${ }^{7}$. Also, studies in the USA, ("Six Cities" and ACS) showed that even at low concentrations, air pollution exposure was associated with an increase in respiratory and cardiovascular mortality ${ }^{8,9}$. Since then it has not been possible to establish a threshold below which no adverse effects on health were found. Furthermore, it has been shown that air pollution exposure was not only associated with acute health effects, but also that long-term air pollution exposure was associated with chronic health effects.

The effects of air pollution on asthma are biologically possible as air pollution causes inflammation and oxidative stress, i.e. mechanisms that are involved in asthma exacerbation, asthma severity, and probably in asthma development as well ${ }^{10}$. Particulate matter is categorized on the basis of its aerodynamic diameter and causes inflammation and oxidative stress in the lung at various levels, depending on the site of deposition when inhaled. Gases also interact with the lung at several levels (Fig. 1). In asthmatic volunteers, controlled exposures to sulphur dioxide $\left(\mathrm{SO}_{2}\right), \mathrm{O}_{3}$, and $\mathrm{NO}_{2}$ at levels that are found in real-life situations induced bronchial hyperresponsiveness and inflammation and reduced the dose of aeroallergen needed to produce a given bronchial response. 


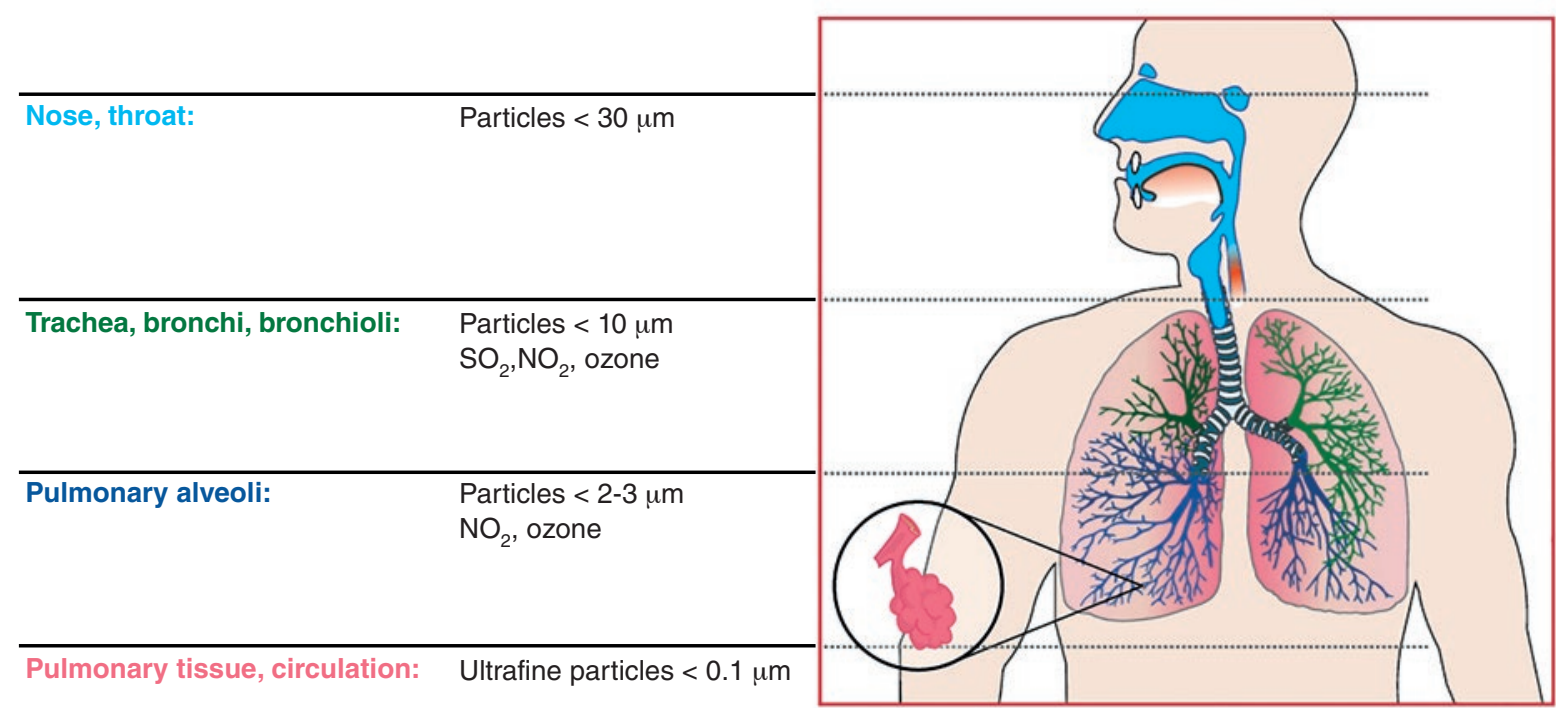

Figure 1. Particulate matter and gases - interactions with respiratory tract. Particulate matter is categorized on the basis of its aerodynamic diameter, depending on site of deposition when inhaled. Gases cause lung damage at all the levels.

$\mathrm{NO}_{2}$ : nitrogen dioxide; $\mathrm{SO}_{2}$ : sulphur dioxide.

The role of air pollutants in triggering asthma exacerbations in asthma patients has been established since many years. Several studies, although not all, support the role of air pollution or traffic proximity in the development of asthma in childhood. The role of air pollution in adult-onset asthma (i.e., asthma incidence) has been investigated in fewer studies and should not be extrapolated from studies in children because they are two distinct asthma phenotypes that have, at least partly, different clinical, biological, and genetic characteristics $^{4}$. Although we will not address it in this manuscript, it is important to note that there is also literature on the effects of air pollution on asthma-related traits or phenotypes, such as asthma control or severity, or atopy in asthmatics. Very briefly, it seems that air pollution could be associated with more severe attacks of asthma ${ }^{11}$ and a more severe asthma ${ }^{12}$, and also with a poorer control of the disease ${ }^{13,14}$. Regarding atopy, the literature is even less consistent and has mainly focused in children. For the moment, it is not possible to draw a firm conclusion about the effects on allergy, however some studies suggest that air pollution could be associated with atopy in children ${ }^{15,16}$ or higher levels of immunoglobulin $\mathrm{E}$ in subjects with asthma, but not in those without ${ }^{17}$. Furthermore, a recent study showed that the effects of $\mathrm{NO}_{2}$ on childhood asthma were modified by the presence of other allergic diseases, such as allergic rhinitis, eczema, or food allergy, suggesting a probable role for allergic sensitization in the pathogenesis of air pollution-related asthma ${ }^{18}$.

In this manuscript, we will summarize the evidence for the role of air pollution on (i) asthma exacerbations, (ii) asthma incidence in 
children, and (iii) asthma incidence in adults, highlighting the most important publications in each of these three areas.

\section{ASTHMA EXACERBATIONS}

Air pollution epidemiology started in the 1970s by studying the short-term effects of air pollution on mortality and hospitalization and by focusing on respiratory causes, including those related to asthma. The effect of shortterm exposure to air pollution on acute manifestations of the disease is usually assessed with time-series or panel studies. The markers of asthma exacerbations that were more frequently studied were hospitalizations or emergency visits due to asthma. In the 1980s, many studies showed an increase in hospital admissions due to asthma associated with $\mathrm{O}_{3}$ and particles exposure in adults, children, and the elderly. Most of these studies were conducted in the USA ${ }^{19}$. They all described the health effects at concentrations below the North American air quality standards. One of the first studies in Europe showing an association between air pollution and asthma emergency visits was conducted in Barcelona. They showed that black smoke and $\mathrm{NO}_{2}$ were associated with asthma visits, but they did not find associations with $\mathrm{SO}_{2}$ and $\mathrm{O}_{3}{ }^{20}$. These results were confirmed in a study that included four European cities: Barcelona, Helsinki, London, and Paris within the framework of APHEA (Air Pollution and Health: A European Approach). They showed a significant increase in daily admissions for asthma in adults associated with $\mathrm{NO}_{2}$ and non-significantly with black smoke. The association between asthma admissions and $\mathrm{O}_{3}$ was heterogeneous among cities. In children, daily admissions increased significantly with $\mathrm{SO}_{2}$ and non-significantly with black smoke and $\mathrm{NO}_{2}{ }^{21}$. Routine PM monitoring in Europe appeared after those for gases and a few years later, within the context of APHEA 2, it was confirmed that particle concentrations in eight European cities were positively associated with increased numbers of admissions for asthma in children and adults ${ }^{22}$. Since then, many studies have confirmed such associations for gases and particles for adults and children (e.g., the multicenter studies by Bell et al. ${ }^{23}$, Dominici et al. ${ }^{24}$, and Staffogia et al. ${ }^{25}$ ). Selected articles are summarized in table 1 . These results on emergency admissions as markers of exacerbations have been validated with other acute markers of the disease such as doctor's or emergency departments' visits ${ }^{26-28}$, medication intake ${ }^{29,30}$, or absenteeism ${ }^{31}$.

Recently, several studies have tried to identify the component or the source of pollution associated with asthma hospitalizations. Basagaña et al. ${ }^{32}$ found in Europe an increase in respiratory hospitalization with several PM constituents such as elemental carbon or nickel. Such elements come from different sources and some of them are highly correlated and therefore it was difficult to attribute effects to a particular constituent or to identify any source specifically. In the USA, adverse associations with paediatric asthma were observed with particles generated from diesel-fuelled vehicles and gasoline-fuelled vehicles ${ }^{33}$, while in another study they found that emergency visits for paediatric asthma were strongly associated with high exposures on days with multi-pollutant mixtures; but they could not identify any specific combinations that were more harmful than others ${ }^{28}$. However, a very important and interesting experimental real-life 
TABLE 1. Key epidemiological papers regarding the short-term effects of air pollution on asthma exacerbations

\begin{tabular}{|c|c|c|}
\hline Reference & Brief description of the study & Key findings \\
\hline Sunyer et al. ${ }^{21}$ & $\begin{array}{l}\text { Multi-city time series, } 4 \text { European cities. 1986-92. } \mathrm{O}_{3} \\
\mathrm{NO}_{2}, \mathrm{SO}_{2}\end{array}$ & $\begin{array}{l}\text { Daily admissions for asthma in adults increased with } \mathrm{NO}_{2} \text {. } \\
\text { In children, daily admissions increased with } \mathrm{SO}_{2}\end{array}$ \\
\hline Atkinson et al. ${ }^{22}$ & $\begin{array}{l}\text { Multi-city time series, } 8 \text { European cities. 1988-1997. } \mathrm{PM}_{10^{\prime}} \\
\mathrm{O}_{3^{\prime}} \mathrm{NO}_{2}, \mathrm{SO}_{2}, \mathrm{CO}\end{array}$ & $\begin{array}{l}\mathrm{PM} \text { is associated with increased admissions for } \\
\text { respiratory diseases }\end{array}$ \\
\hline Bell et al. ${ }^{24}$ & $\begin{array}{l}\text { Multi-site time-series models in } 202 \text { US counties. } \\
\text { 1999-2005. } \mathrm{PM}_{2.5}\end{array}$ & $\mathrm{PM}_{2.5}$ was associated with respiratory admissions \\
\hline Dominici et al. ${ }^{25}$ & $\begin{array}{l}\text { Multi-site time-series models in } 204 \text { US counties. } \\
\text { 1999-2002. } \mathrm{PM}_{2.5}\end{array}$ & $\begin{array}{l}\mathrm{PM}_{2.5} \text { increases hospital admission for respiratory } \\
\text { diseases }\end{array}$ \\
\hline Stafoggia et al. ${ }^{26}$ & $\begin{array}{l}\text { Multi-city time series, } 8 \text { European cities. 2001-2010. } \text { PM }_{10^{\prime}} \\
\text { PM }_{2.5^{\prime}} \text { PMcoarse }\end{array}$ & $\begin{array}{l}\mathrm{PM}_{2.5} \text { and } \mathrm{PMcoarse} \text { were associated with respiratory } \\
\text { hospitalizations }\end{array}$ \\
\hline
\end{tabular}

CO: carbon monoxide; $\mathrm{NO}_{2}$ : nitrogen dioxide; $\mathrm{O}_{3}$ : ozone; $\mathrm{SO}_{2}$ : sulphur dioxide; $\mathrm{PM}$ : particulate matter; $\mathrm{PM}_{10}$ : particulate matter with an aerodynamic diameter $\leq 10 \mu \mathrm{m}$; $\mathrm{PM}_{2.5}$ : particulate matter with an aerodynamic diameter $\leq 2.5 \mu \mathrm{m}$; PMcoarse: particulate matter with an aerodynamic diameter $\leq 10 \mu \mathrm{m}$ and $\geq$ than $2.5 \mu \mathrm{m}$.

condition study (detailed in the discussion) showed that exposure demonstrated a causal nature in the functional exacerbation (forced expiratory volume in one second, $\mathrm{FEV}_{1}$, decline in asthmatics) due to diesel particles ${ }^{34}$.

The literature on asthma symptoms associated with long term-exposure to air pollution is very extensive, suggesting also a chronic effect of air pollution in asthma expression in both children $^{35,36}$ and adults ${ }^{37-39}$.

\section{ASTHMA INCIDENCE IN CHILDREN}

The research on the chronic long-term effects of exposure to air pollution in asthma is more recent than the research on its acute effects, mainly due to the development of new methods to assess long-term exposure to air pollution. The long-term effect of air pollution on new-onset asthma has been mostly studied in children ${ }^{40}$ and is quite extensive. In children, proximity to traffic is associated with an increase in asthma prevalence and incidence ${ }^{41-43}$, with substantial evidence for a causal asthmogenic role of the pollutants occurring in high concentrations along busy roads. The Southern California Children's Health Study contributed with several analyses to the evidence that proximity to traffic or air pollution was associated with asthma ${ }^{41,42,44}$. They also found that long-term exposure in early childhood was associated with impaired lung development, as we will detail later ${ }^{45}$. These results were confirmed by several European studies ${ }^{43,46}$. Within the Spanish INMA cohort (Childhood and Environment), it was observed that early-life exposure to ambient air pollution may increase the risk of upper and lower respiratory tract infections in infants ${ }^{47}$. These results were confirmed within the context of ESCAPE including INMA and another six European cohorts ${ }^{48}$. Selected articles are summarized in table 2.

In the literature on children, it is interesting to note that proximity to traffic, more than air pollution exposure per se, seems to be associated with asthma. For example, in the European ESCAPE study ${ }^{49}$ including five cohorts, the authors did not find an association between modelled air pollution and childhood 
TABLE 2. Key epidemiological papers regarding the long-term exposure of air pollution on asthma onset in children

\begin{tabular}{|c|c|c|}
\hline Reference & Brief description of the study & Key findings \\
\hline Jerrett et al. ${ }^{41}$ & $\begin{array}{l}217 \text { children from the Southern California Children's Health Study, } \\
\text { followed up from the age of } 10 \text { to } 18 \text {. Home } \mathrm{NO}_{2} \text { monitors }\end{array}$ & $\begin{array}{l}\mathrm{NO}_{2} \text { was associated with the onset of } \\
\text { asthma }\end{array}$ \\
\hline McConnell et al. ${ }^{42}$ & $\begin{array}{l}\text { 2,497 4-6 year old children from the Southern California Children's } \\
\text { Health Study followed-up for } 3 \text { years. Central monitoring } \mathrm{O}_{3^{3}} \mathrm{PM} \text { and } \\
\mathrm{NO}_{2} \text { and traffic-related air pollution derived from dispersion models }\end{array}$ & $\begin{array}{l}\text { Both proximity to traffic and } \mathrm{NO}_{2} \text { were } \\
\text { associated with asthma onset }\end{array}$ \\
\hline Gehring et al..$^{43}$ & $\begin{array}{l}\text { Birth cohort study with an 8-year follow-up. } \mathrm{NO}_{2}, \mathrm{PM}_{2.5} \text { and soot } \\
\text { estimated by land-use regression models }\end{array}$ & $\begin{array}{l}\mathrm{PM}_{2.5^{\prime}} \mathrm{NO}_{2} \text { and soot were associated with } \\
\text { incidence of asthma, prevalence of asthma, } \\
\text { and prevalence of asthma symptoms }\end{array}$ \\
\hline Gauderman et al. ${ }^{44}$ & $\begin{array}{l}208 \text { children from the Children's Health Study, followed up from the } \\
\text { age of } 10 \text { to } 18 \text {. Home } \mathrm{NO}_{2} \text { monitors and distance to freeways } \\
\text { derived by geographic information systems }\end{array}$ & $\begin{array}{l}\mathrm{NO}_{2} \text { and distance to freeways were } \\
\text { associated with asthma incidence }\end{array}$ \\
\hline Brauer et al. ${ }^{46}$ & $\begin{array}{l}4,000 \text { children followed-up from birth to } 4 \text { years. } \mathrm{NO}_{2} \text { and } \mathrm{PM}_{2.5} \\
\text { estimated by land-use regression models }\end{array}$ & $\begin{array}{l}\text { Traffic-related pollution was associated with } \\
\text { doctor-diagnosed asthma }\end{array}$ \\
\hline Mölter et al. ${ }^{49}$ & $\begin{array}{l}\text { Five European cohorts. } \mathrm{NO}_{2}, \mathrm{NOx}, \mathrm{PM}_{10}, \mathrm{PM}_{2.5} \text {, black smoke derived } \\
\text { from land use regression models }\end{array}$ & $\begin{array}{l}\text { No significant association between air } \\
\text { pollution exposure and childhood asthma } \\
\text { prevalence }\end{array}$ \\
\hline
\end{tabular}

$\mathrm{NO}_{2}$ : nitrogen dioxide; NOx: nitrogen oxides; $\mathrm{O}_{3}$ : ozone; $\mathrm{PM}$ : particulate matter; $\mathrm{PM}_{10}$ : particulate matter with an aerodynamic diameter $\leq 10 \mu \mathrm{m} ; \mathrm{PM}_{2.5}:$ particulate matter with an aerodynamic diameter $\leq 2.5 \mu \mathrm{m}$.

asthma prevalence, but they did not test for proximity to traffic. While the evidence supporting the negative effect of air pollution on asthma incidence is still quite accepted, this issue raises the question of which air pollution element or source is the one causing negative health effects in children, and evidence is pointing to combustion/diesel exhaust.

Another issue we would like to discuss is that time of exposure could be particularly important regarding respiratory health in children. Morales et $a .^{50}$ found that prenatal exposure to residential traffic-related air pollution was associated with long-term lung function deficits at preschool age. These results are closely related to the growing and solid evidence in the literature associating prenatal exposure to air pollution with low birth weight ${ }^{51,52}$, as it is well known that birth weight has an impact on health at later ages, including respiratory health. Therefore, prenatal exposure to air pollution could play an important role in later asthma development.

\section{ASTHMA INCIDENCE IN ADULTS}

The evidence is less extensive in adult-onset than in childhood asthma ${ }^{40}$. The earliest study to identify an association between long-term exposure to air pollution (i.e., $\mathrm{O}_{3}$ ) and asthma incidence was a cohort of non-smoking Californian Seventh-Day Adventists assessing the long-term health effects of ambient air pollutants (AHSMOG). They found a positive association, but only for males ${ }^{53}$. The study by Modig et al. ${ }^{54}$ was the first to investigate the contribution of traffic-related pollution to adult-onset asthma, and suggested an association of traffic-related $\mathrm{NO}_{2}$ with asthma incidence, but the study lacked statistical power. The Respiratory Health in Northern Europe study ${ }^{55}$ and the European Community Respiratory 
TABLE 3. Key epidemiological papers regarding the long-term exposure of air pollution on asthma onset in adults

\begin{tabular}{|c|c|c|}
\hline Reference & Brief description of the study & Key findings \\
\hline McDonnell et al..$^{53}$ & $\begin{array}{l}\text { Cohort of 3,091 nonsmoker adults (age, 27-87) in US, } \\
\text { followed up for } 15 \text { years. } \mathrm{PM}_{10^{\prime}} \mathrm{SO}_{4^{\prime}} \mathrm{NO}_{2}, \mathrm{SO}_{2}, \mathrm{O}_{3^{\prime}} \text { and } \\
0_{3} 8 \text {-hour average from the closest fixed monitoring } \\
\text { stations }\end{array}$ & $\begin{array}{l}\mathrm{O}_{3} 8 \text {-hour average was associated with adult asthma } \\
\text { incidence in males }\end{array}$ \\
\hline Modig et al. ${ }^{54}$ & $\begin{array}{l}203 \text { cases and } 203 \text { controls in Sweden, aged from } 20 \text { to } \\
60 \text {. Home } \mathrm{NO}_{2} \text { monitors and proximity to traffic }\end{array}$ & $\begin{array}{l}\text { Living close to high traffic was non-significantly } \\
\text { associated with asthma incidence } \\
\mathrm{NO}_{2} \text { was associated with adult asthma incidence only } \\
\text { in subjects with a positive SPT }\end{array}$ \\
\hline Modig et al..$^{55}$ & $\begin{array}{l}\text { Cohort in Sweden, including } 3,824 \text { adults (age, } 15-45 \text { ), } \\
\text { followed-up for } 9 \text { years. } \mathrm{NO}_{2} \text { dispersion models and } \\
\text { proximity to traffic }\end{array}$ & $\begin{array}{l}\mathrm{NO}_{2} \text { exposure and living close to a major road were } \\
\text { associated with asthma onset and incidence in adults }\end{array}$ \\
\hline Jacquemin et al..$^{56}$ & $\begin{array}{l}\text { Prospective cohort, in European } 17 \text { cities (ECRHS), } \\
\text { including 4,185 adults (age, 20-40) followed up for } 10 \\
\text { years. } \mathrm{NO}_{2} \text { dispersion models }\end{array}$ & $\mathrm{NO}_{2}$ was associated with asthma incidence in adults \\
\hline Kunzli et al..$^{57}$ & $\begin{array}{l}\text { Prospective cohort in } 8 \text { Swiss areas, including } 2,725 \\
\text { adults (age,18-60), followed up for } 10 \text { years, } \\
\text { traffic-related } \text { PM }_{10} \text { dispersions model }\end{array}$ & $\begin{array}{l}\text { Traffic } \mathrm{PM}_{10} \text { is associated with asthma incidence in } \\
\text { adult nonsmokers }\end{array}$ \\
\hline Young et al..$^{58}$ & $\begin{array}{l}\text { US cohort including } 50,884 \text { women followed up for } 5 \text { years } \\
\mathrm{PM}_{2.5} \text { and } \mathrm{NO}_{2} \text { Kriging models }\end{array}$ & $\mathrm{PM}_{2.5}$ and $\mathrm{NO}_{2}$ were associated with asthma incidence \\
\hline Jacquemin et al..$^{59}$ & $\begin{array}{l}6 \text { European cohorts of adults followed up for around } 10 \\
\text { years. } \mathrm{NO}_{2}, \mathrm{NOx}, \mathrm{PM}_{10^{\prime}} \mathrm{PM}_{2.5^{\prime}} \text {, black smoke derived } \\
\text { from land-use regression models }\end{array}$ & $\begin{array}{l}\mathrm{NO}_{2} \text { was borderline significant associated with asthma } \\
\text { incidence }\end{array}$ \\
\hline
\end{tabular}

$\mathrm{NO}_{2}$ : nitrogen dioxide; $\mathrm{O}_{3}$ : ozone; $\mathrm{SO}_{2}$ : sulphur dioxide; $\mathrm{PM}$ : particulate matter; $\mathrm{PM}_{10}$ : particulate matter with an aerodynamic diameter $\leq 10 \mu \mathrm{m} ; \mathrm{PM}_{2.5}:$ particulate matter with an aerodynamic diameter $\leq 2.5 \mu \mathrm{m}$.

Health Survey ${ }^{56}$ also reported a positive association between $\mathrm{NO}_{2}$ and asthma incidence. In the latter cohort, results were confirmed using asthma definition-based symptoms ${ }^{39}$. The Swiss study on air pollution and health in adults found similar results, but using the traffic fraction of PM and only in never-smok$\mathrm{ers}^{57}$. A recent US study suggested an association of particulate matter with an aerodynamic diameter $\leq 2.5 \mu \mathrm{m}\left(\mathrm{PM}_{2.5}\right)$ with incident asthma in women ${ }^{58}$. Within the context of the European Study of Cohorts for Air Pollution Effects (ESCAPE) including six cohorts, the authors also found that asthma incidence was positively associated with $\mathrm{NO}_{2}$ but lacked the power to find an association with $\mathrm{PM}^{59}$. Even if, compared to the child literature, evidence is less extensive, it strongly suggests that air pollution could also be associated with asthma incidence in adults. Selected articles are summarized in table 3.

\section{INTERPRETATION OF FINDINGS}

Air pollution is associated with acute and chronic manifestations of asthma and very probably also associated with asthma onset in both children and adults (Table 4). However, some issues still need to be discussed and clarified so we will raise some of these in the following sections.

Disentangling the chronic and acute effects of air pollution is a challenge in air pollution epidemiology. In the case of asthma, as shown 
previously, it appears that air pollution could be associated with both aspects, namely worsening of the pre-existent disease but also causing the disease. However, the underlying mechanisms through which air pollution could be associated with these two facets of the disease are still unclear, though it is likely that in both cases the effects are mediated by oxidative stress and inflammation ${ }^{60-63}$. But mechanisms could be specific per pollutant. As alluded to above, evidence points towards combustion and diesel particle exposure as being responsible for asthma development in children. In child studies, it has been suggested that the mechanisms linked to asthma incidence include allergic sensitization, and diesel exhaust may act as an adjuvant affecting the immune response to environmental allergens, and air pollutant particles may act as carriers of microbes and allergens ${ }^{64,65}$.

One of the main challenges for studies addressing the health impact of air pollution is the assessment of exposure. Similar to the need to define the phenotypes and biologic features of study participants, exposure to ambient air pollution has to be assessed at an individual level. Numerous studies on the effects of air pollution are based on studies characterizing urban background pollution and/or the daily changes of key markers of this mixture. More recent approaches substantially improved the assessment of local contrasts occurring particularly in those pollutants and constituencies that heavily depend on proximity to sources, such as traffic-related primary pollutants ${ }^{66}$. However, personal assessment of exposures, integrating the various spaces people spent time and commute in, has so far been restricted to small-scale studies. All methods have advantages and limitations, but there is
TABle 4. Summary of the air pollutant effects on asthma

\begin{tabular}{|l|c|c|c|}
\hline \multirow{2}{*}{ Pollutant } & \multirow{2}{*}{$\begin{array}{c}\text { Acute } \\
\text { effects }\end{array}$} & \multicolumn{2}{|c|}{ Chronic effects } \\
\cline { 3 - 4 } & & Children & Adults \\
\hline Particulate matter & ++ & ++ & - \\
\hline Nitrogen dioxide & +++ & ++ & ++ \\
\hline Ozone & +++ & NA & NA \\
\hline Traffic proximity & NA & ++ & - \\
\hline $\begin{array}{l}\text { - not sufficient evidence; + some studies find associations; ++ most studies find } \\
\text { consistent results; +++ almost all studies find consistent results; NA: not available. }\end{array}$
\end{tabular}

no consensus on a "gold standard" -which also depends on the study design- and their development depends on the resources avail$a^{a b l e}{ }^{66}$. A general challenge of exposure assessment, in particular in studies on the longterm effects of air pollution, is the scaling-up to large populations. Novel remote sensing, satellite-based tools combined with local measurements and land-use information may become highly attractive to define air quality retrospectively and prospectively in space and time (Fig. 2 and 3) ${ }^{67}$. The combination of the pollution space with individually collected information on time-activity patterns, using personal mobile micro technology, will further improve the assessment of exposure on various time scales and for specific sources. The improvement of air pollution exposure assessment in a fine geographical scale on large populations, taking into account time-activity patterns, will allow us to better characterize and understand air pollution effects on asthma.

Air pollution is a mixture of multiple pollutants, some of them being highly correlated to each other either in time or space, if not both, making it difficult to identify the causal pollutants. It is interesting to note that American 


\section{BRN Rev. 2015;1}

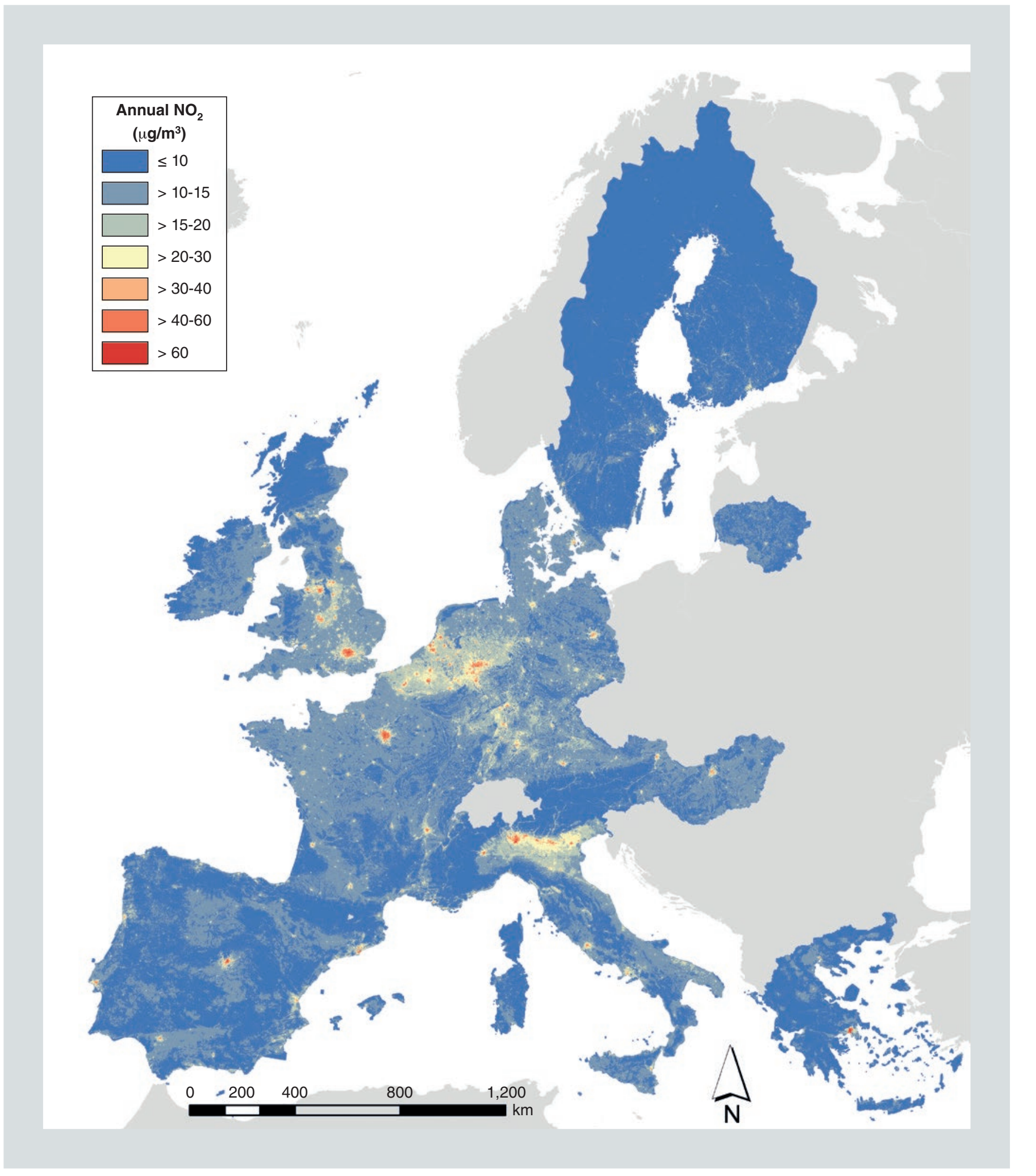

Figure 2. Map of nitrogen dioxide concentrations in 2005. Nitrogen dioxide $\left(\mathrm{NO}_{2}\right.$ ) LUR models for Western Europe (years: 2005-2007) based on > 1,500 EuroAirnet monitoring sites covering background, industrial, and traffic environments. Predictor variables include land use characteristics, population density, and length of major and minor roads in zones from 0.1 to $10 \mathrm{~km}$, altitude, and distance to sea. The models were improved using satellite-based data (reprinted with permission from Vienneau et al. ${ }^{67}$. Copyright 2013 American Chemical Society). 


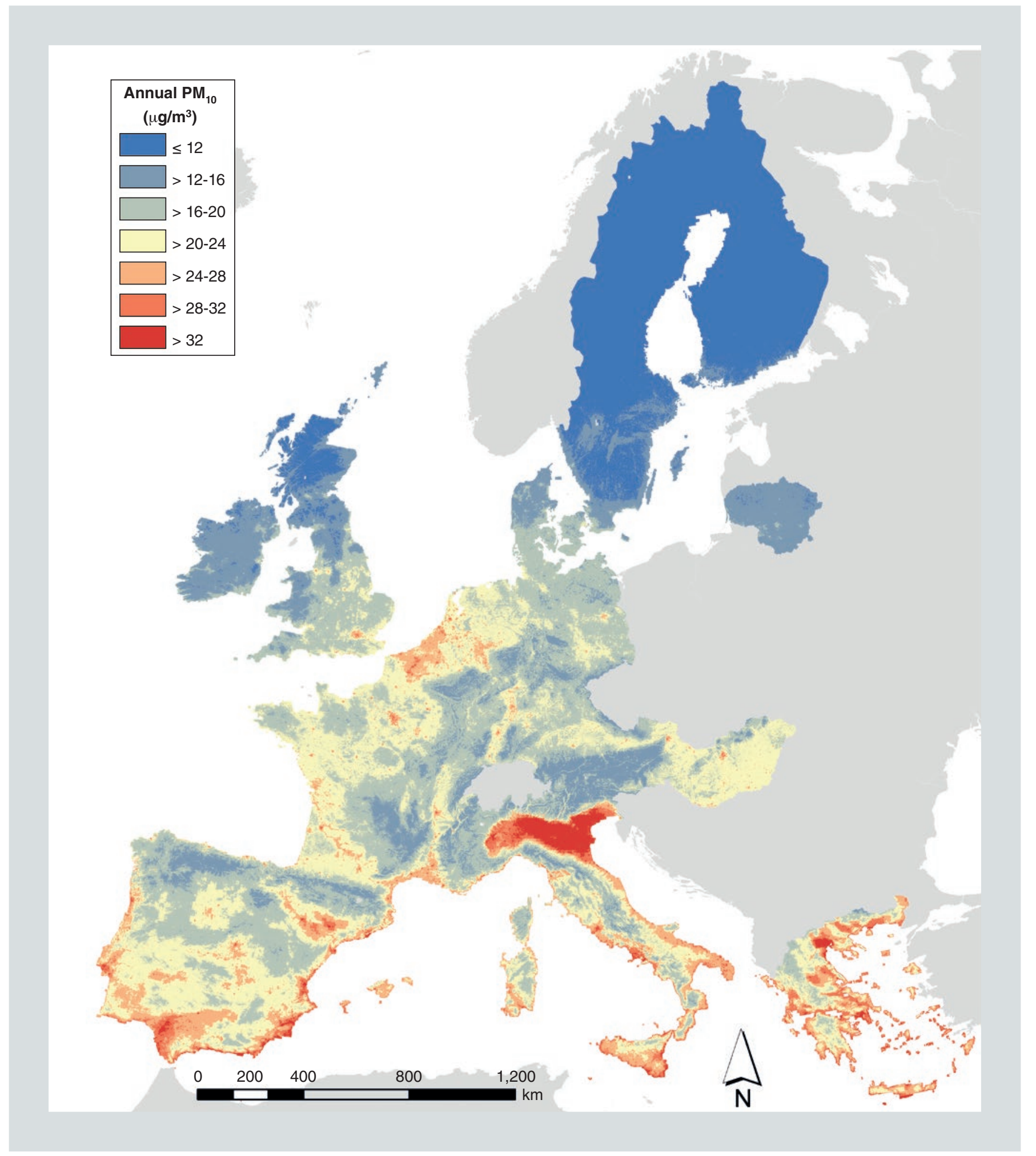

FIGURE 3. Map of particulate matter with an aerodynamic diameter $\leq 10 \mu \mathrm{m}$ concentrations in 2010. Nitrogen dioxide LUR models for Western Europe (years: 2005-2007) based on > 1,500 EuroAirnet monitoring sites covering background, industrial, and traffic environments.

Predictor variables include land use characteristics, population density, and length of major and minor roads in zones from 0.1 to $10 \mathrm{~km}$, altitude, and distance to sea. The models were improved using satellite-based data (reprinted with permission from Vienneau et al. ${ }^{67}$. Copyright 2013 American Chemical Society).

$\mathrm{PM}_{10}$ : particulate matter with an aerodynamic diameter $\leq 10 \mu \mathrm{m}$. 
studies tend to find more negative effects of air pollution on asthma with PM or proximity to traffic and European studies with gases, namely $\mathrm{NO}_{2}$. This could be due in part to the fact that particles have been measured routinely for more time in American cities, thus having more perspective for PM. Also, $\mathrm{NO}_{2}$ is a marker of traffic and particularly of ultrafine particles. While in relation to mortality $\mathrm{NO}_{2}$ is generally seen as a marker of traffic exposure, being an oxidant in relation to asthma attacks, it could play a causal role as a trigger. Another explanation could be that particle composition differs from one place to another. In fact, the notion of a "culprit pollutant" may be inherently flawed as pollutants contained in the mixture may act synergistically or even antagonistically. Characterizing exposure to "clustered" and source-specific pollutants at the personal level may have major advantages. To the extent that health effects depend on the nature and toxicity of pollutants, markers of such features of the mixture may be particularly appealing to address mechanisms and susceptibility factors.

We would like to draw attention to the literature about air pollution and lung function, which is a phenotype closely related to asthma. Numerous epidemiologic studies have shown decrements in pulmonary function that were associated with short-term air pollution exposure under real exposure conditions ${ }^{68}$. In 2007, Mc Creanor et al. ${ }^{34}$ conducted a very interesting experimental real-life exposure study, including 60 adults with asthma. Each participant walked for two hours in a very busy London street (Oxford Street) and, at a separate time, in a London park (Hyde Park). They found larger reductions in the $\mathrm{FEV}_{1}$ and forced vital capacity (FVC) after walking in the street compared with walking in the park. The changes were greater in subjects with moderate asthma compared with those with mild asthma. These lung function test abnormalities were accompanied by increases in biomarkers of lung inflammation. These results contributed to confirm and better understand the acute effects of air pollution on the lung in asthmatics. Furthermore, long-term exposure to air pollution has also been associated with lung function growth ${ }^{45}$, levels ${ }^{69}$, and decline ${ }^{70,71}$. The study by Gauderman et al. ${ }^{45}$ was particularly important as it was one of the first to show prospectively in a large cohort that local exposure to traffic had adverse effects on children's lung development, which could cause an impaired lung function in later life. All these features are implicated in both asthma aetiology and severity and very likely share mechanisms with asthma.

Another issue that we would like to discuss is whether it has been possible to identify susceptibility factors in the association between air pollution and asthma, in particular related to sex, atopy, or smoking. Actually, these factors have not systematically been addressed and the results are inconsistent. For example, as we have seen, many studies have found that air pollution was associated with atopy and/or asthma, but most of them lacked the power to address the question if air pollution was more associated with atopic asthma or non-atopic asthma, and those that looked for such interactions reported inconsistent associations. While results concerning sex differences are also inconsistent, some but not all seemed to find a higher association in males. It is interesting to note that in a prospective European meta-analysis including six cohorts, sex did not modify the associations between $\mathrm{NO}_{2}$ and asthma incidence ${ }^{59}$. Furthermore, all 
cohorts showed positive associations between air pollution and asthma incidence in adults, except the Etude Epidémiologique auprès de femmes de la MGEN (Mutuelle Générale de l'Education Nationale) (E3N) cohort that only includes older women, mostly teachers ${ }^{59}$. However, conversely, results from a nationwide US cohort suggest that air pollution exposure increases the risk of developing asthma in adult women ${ }^{58}$. Regarding smoking, air pollution may be plausibly more asthmogenic in non-smokers, and several studies found greater associations between air pollution and asthma in non-smokers ${ }^{57,58}$, but there is not sufficient evidence to draw a conclusion. Another interesting question is whether genes, mainly the ones involved in oxidative-nitrosative stress or inflammation pathways, may modulate the associations between air pollution and asthma. A recent review ${ }^{72}$ concluded that there is some evidence for an association between polymorphisms in inflammatory and immune-response genes and adverse respiratory outcomes from exposure to air pollution. However, the authors warned that more research is needed to confirm and quantify the strength of the interactions and to understand the mechanisms behind them.

To conclude the discussion, we would like to highlight several studies that have shown that efforts to reduce exposure are associated with lung function or asthma improvement. In a Swiss prospective cohort, decreasing exposure to airborne particulates appeared to attenuate the decline in lung function related to exposure to particulate matter with an aerodynamic diameter $\leq 10 \mu \mathrm{m}\left(\mathrm{PM}_{10}\right)^{71}$. In another Swiss study, it was observed that the reduction of PM exposures improved respiratory health in children $^{73}$. More recently, Adar et al..$^{74}$ found that national and local diesel policies have reduced air pollutant concentrations exposures in the USA, so such decrease in exposure was associated with improved fractional exhaled $\mathrm{NO}_{2}$ $\mathrm{FEV}_{1}$ and FVC growth, and absenteeism, principally in children with asthma. And Gauderman et al. ${ }^{75}$, as part of the Children's Health Study, found that long-term improvements in air quality were associated with statistically and clinically significant positive effects on lung-function growth in children. Whether all these improvements will actually result in fewer cases of asthma in the future still needs to be studied, but these results are promising.

\section{CONCLUSION}

There is growing and solid evidence that air pollution causes asthma exacerbations. The evidence regarding the effect of air pollution exposure on asthma onset is also quite robust, mainly in children but also in adults. Furthermore, there is a lot of knowledge about the mechanisms of the different pollutants involved. Gases that are oxidants could be more associated with acute manifestations of the disease, and particles that are more related with chronic inflammation could be more related to incidence. Diesel particles have been associated with both exacerbations and incidence. However, research is still needed to better understand and identify the underlying mechanisms related to the specific pollutants and specific sources. More research is also needed to identify more susceptible groups such as males, non-smokers, or persons with other chronic conditions, such as atopy or obesity. To achieve such goals, well-characterized and phenotyped large cohorts with detailed exposure assessment are necessary. 
In the light of these results that show that air pollution exposure, and principally traffic-related air pollution exposure, has a major impact on respiratory health, the pulmonologists, as they did against the tobacco industry, should act as lobbyists and put pressure on local and European authorities in order to promote policies to better control emissions and therefore improve the respiratory health of the population.

\section{CONFLICT OF INTEREST}

\section{All authors declare no relevant conflict of interest}

\section{REFERENCES}

1. Eder W, Ege MJ, von Mutius E. The Asthma Epidemic. N Engl J Med. 2006;355:2226-35.

2. Murray CJ, Vos T, Lozano R, et al. Disability-adjusted life years (DALYs) for 291 diseases and injuries in 21 regions, 1990-2010: a systematic analysis for the Global Burden of Disease Study 2010. Lancet. 2012;380:2197-223.

3. Strachan DP1, Butland BK, Anderson HR. Incidence and prognosis of asthma and wheezing illness from early childhood to age 33 in a national British cohort. Br Med J. 1996;312:1195-9.

4. Wenzel SE. Asthma phenotypes: The evolution from clinical to molecular approaches. Nat Med. 2012;18:716-25.

5. Bekclake MR, Ernst P. Environmental factors. Lancet. 1997;350(Suppl 2): SII10-3

6. Brunekreef B, Holgate ST. Air pollution and health. Lancet. 2002;19;360:1233-42.

7. Sunyer J, Sáez M, Murillo C, Castellsague J, Martínez F, Antó JM. Air pollution and emergency room admissions for chronic obstructive pulmonary disease: a 5-year study. Am J Epidemiol. 1993;137:701-5.

8. Dockery DW, Pope CA 3rd, Xu X, et al. An association between air pollution and mortality in six U.S. cities. N Engl J Med. 1993;329:1753-9.

9. Pope CA 3rd, Thun MJ, Namboodiri MM, et al. Particulate air pollution as a predictor of mortality in a prospective study of U.S. adults. Am J Respir Crit Care Med. 1995;151:669-74.

10. Guarnieri M, Balmes JR. Outdoor air pollution and asthma. Lancet. 2014;383:1581-92.

11. Sunyer J, Basagaña X, Belmonte J, Antó JM. Effect of nitrogen dioxide and ozone on the risk of dying in patients with severe asthma. Thorax. 2002;57:687-93.

12. Rage E, Siroux V, Kunzli N, Pin I, Kauffmann F. Air pollution and asthma severity in adults. Occup Environ Med. 2009:66:182-8.

13. Jacquemin B, Kauffmann F, Pin I, et al. Air pollution and asthma control in the Epidemiological study on the Genetics and Environment of Asthma. J Epidemiol Community Health. 2012;66:796-802.

14. Meng YY1, Wilhelm M, Rull RP, English P, Ritz B. Traffic and outdoor air pollution levels near residences and poorly controlled asthma in adults. Ann Allergy Asthma Immunol. 2007;98:455-63.
15. Morgenstern V, Zutavern A, Cyrys J, et al. Atopic diseases, allergic sensitization, and exposure to traffic-related air pollution in children. Am J Respir Crit Care Med. 2008;177:1331-7.

16. Gruzieva O, Bellander T, Eneroth $\mathrm{K}$, et al. Traffic-related air pollution and development of allergic sensitization in children during the first 8 years of life. J Allergy Clin Immunol. 2012;129:240-6.

17. Rage E, Jacquemin B, Nadif R, et al. Total serum IgE levels are associated with ambient ozone concentration in asthmatic adults. Allergy. 2009:64:40-6.

18. Dell SD, Jerrett M, Beckerman B, et al. Presence of other allergic disease modifies the effect of early childhood traffic-related air pollution exposure on asthma prevalence. Environ Int. 2014;65:83-92.

19. Lipfert FW. A critical review of studies of the association between demands for hospital services and air pollution. Environ Health Perspect. 1993;101(Suppl 2):229-68.

20. Castellsague J, Sunyer J, Sáez M, Antó JM. Short-term association between air pollution and emergency room visits for asthma in Barcelona. Thorax 1995;50:1051-6

21. Sunyer J, Spix C, Quenel P, et al. Urban air pollution and emergency admissions for asthma in four European cities: the APHEA Project. Thorax 1997:52:760-5.

22. Atkinson RW, Anderson HR, Sunyer J, et al. Acute effects of particulate air pollution on respiratory admissions: results from APHEA 2 project. Air Pollution and Health: a European Approach. Am J Respir Crit Care Med. 2001;164:1860-6.

23. Bell ML, Ebisu K, Peng RD, et al. Seasonal and regional short-term effects of fine particles on hospital admissions in 202 US counties, 1999-2005. Am J Epidemiol. 2008;168:1301-10.

24. Dominici F, Peng RD, Bell ML, et al. Fine particulate air pollution and hospital admission for cardiovascular and respiratory diseases. JAMA 2006;295:1127-34.

25. Stafoggia M, Samoli E, Alessandrini E, et al. Short-term associations between fine and coarse particulate matter and hospitalizations in Southern Europe: results from the MED-PARTICLES project. Environ Health Perspect. 2013;121:1026-33.

26. Hajat S, Haines A, Goubet SA, Atkinson RW, Anderson HR. Association of air pollution with daily GP consultations for asthma and other lower respiratory conditions in London. Thorax 1999:54:597-605.

27. Strickland MJ, Darrow LA, Klein M, et al. Short-term associations between ambient air pollutants and pediatric asthma emergency department visits. Am J Respir Crit Care Med. 2010;182:307-16.

28. Pearce JL, Waller LA, Mulholland JA, et al. Exploring associations between multipollutant day types and asthma morbidity: epidemiologic applications of self-organizing map ambient air quality classifications. Environ Health 2015;14:55.

29. Menichini F1, Mudu P. Drug consumption and air pollution: an overview. Pharmacoepidemiol Drug Saf. 2010;19:1300-15.

30. Gent JF1, Koutrakis P, Belanger K, et al. Symptoms and medication use in children with asthma and traffic-related sources of fine particle pollution. Environ Health Perspect. 2009;117:1168-74.

31. Bener A, Kamal M, Shanks NJ. Impact of asthma and air pollution on school attendance of primary school children: are they at increased risk of school absenteeism? J Asthma. 2007;44:249-52.

32. Basagaña X, Jacquemin B, Karanasiou A, et al. Short-term effects of particulate matter constituents on daily hospitalizations and mortality in five South-European cities: results from the MED-PARTICLES project. Environ Int. 2015;75:151-8

33. Gass K, Balachandran S, Chang HH, Russell AG, Strickland MJ. Ensemble-based source apportionment of fine particulate matter and emergency department visits for pediatric asthma. Am J Epidemiol. 2015;181:504-12.

34. McCreanor J, Cullinan P, Nieuwenhuijsen MJ, et al. Respiratory effects of exposure to diesel traffic in persons with asthma. N Engl J Med. 2007;357:2348-58.

35. McConnell R, Berhane K, Gilliland F, et al. Prospective study of air pollution and bronchitic symptoms in children with asthma. Am J Respir Crit Care Med. 2003;168:790-7. 
36. Holguin F, Flores S, Ross Z, et al. Traffic-related exposures, airway function, inflammation, and respiratory symptoms in children. Am J Respir Crit Care Med. 2007;176:1236-42.

37. Zemp E, Elsasser S, Schindler C, et al. Long-term ambient air pollution and respiratory symptoms in adults (SAPALDIA study). The SAPALDIA Team. Am J Respir Crit Care Med. 1999;159:1257-66.

38. Bayer-Oglesby L, Schindler C, Hazenkamp-von Arx ME, et al. Living near main streets and respiratory symptoms in adults: the Swiss Cohort Study on Air Pollution and Lung Diseases in Adults. Am J Epidemiol. 2006;164:1190-8.

39. Jacquemin B, Sunyer J, Forsberg B, et al. Association between modelled traffic-related air pollution and asthma score in the ECRHS. Eur Respir J. 2009;34: 834-42.

40. Anderson R, Favarato G, Atkinson R. Long-term exposure to air pollution and the incidence of asthma: meta-analysis of cohort studies. Air Qual Atmos Health. 2013;6:47-56.

41. Jerrett M, Shankardass K, Berhane K, et al. Traffic-related air pollution and asthma onset in children: a prospective cohort study with individual exposure measurement. Environ Health Perspect. 2008;116:1433-8.

42. McConnell R, Islam T, Shankardass K, et al. Childhood incident asthma and traffic-related air pollution at home and school. Environ Health Perspect. 2010;118:1021-6.

43. Gehring U, Wijga AH, Brauer M, et al. Traffic-related air pollution and the development of asthma and allergies during the first 8 years of life. Am J Respir Crit Care Med. 2010;181:596-603.

44. Gauderman WJ, Avol E, Lurmann F, et al. Childhood asthma and exposure to traffic and nitrogen dioxide. Epidemiology. 2005;16:737-43.

45. Gauderman WJ, Vora H, McConnell R, et al. Effect of exposure to traffic on lung development from 10 to 18 years of age: a cohort study. Lancet. 2007; 369:571-7.

46. Brauer M, Hoek G, Smit HA, et al. Air pollution and development of asthma, allergy and infections in a birth cohort. Eur Respir J. 2007;29:879-88.

47. Aguilera I, Pedersen M, Garcia-Esteban R, et al. Early-life exposure to outdoor air pollution and respiratory health, ear infections, and eczema in infants from the INMA study. Environ Health Perspect. 2013;121:387-92.

48. MacIntyre EA, Gehring U, Mölter A, et al. Air pollution and respiratory infections during early childhood: an analysis of 10 European birth cohorts within the ESCAPE Project. Environ Health Perspect. 2014;122:107-13.

49. Mölter A, Simpson A, Berdel D, et al. A multicentre study of air pollution exposure and childhood asthma prevalence: the ESCAPE project. Eur Respir J. 2015;45:610-24

50. Morales E, Garcia-Esteban R, de la Cruz OA, et al. Intrauterine and early postnatal exposure to outdoor air pollution and lung function at preschool age. Thorax. 2015;70:64-73.

51. Pedersen M, Giorgis-Allemand L, Bernard C, et al. Ambient air pollution and low birthweight: a European cohort study (ESCAPE). Lancet Respir Med. 2013;1:695-704.

52. Dadvand P, Parker J, Bell ML, et al. Maternal exposure to particulate air pollution and term birth weight: a multi-country evaluation of effect and heterogeneity. Environ Health Perspect. 2013;121:267-373.

53. McDonnell WF, Abbey DE, Nishino N, Lebowitz MD. Long-term ambient ozone concentration and the incidence of asthma in nonsmoking adults: the AHSMOG Study. Environ Res. 1999;80:110-21.

54. Modig L, Järvholm B, Rönnmark E, et al. Vehicle exhaust exposure in an incident case-control study of adult asthma. Eur Respir J. 2006;28:75-81.

55. Modig L, Torén K, Janson C, Jarvholm B, Forsberg B. Vehicle exhaust outside the home and onset of asthma among adults. Eur Respir J. 2009; 33:1261-7.
56. Jacquemin B, Sunyer J, Forsberg B, et al. Home outdoor NO2 and new onset of self-reported asthma in adults. Epidemiology. 2009;20:119-26.

57. Kunzli N, Bridevaux PO, Liu LJ, et al. Traffic-related air pollution correlates with adult-onset asthma among never-smokers. Thorax. 2009;64:664-70.

58. Young MT, Sandler DP, DeRoo LA, Vedal S, Kaufman JD, London SJ. Ambient air pollution exposure and incident adult asthma in a nationwide cohort of U.S. women. Am J Respir Crit Care Med. 2014;190:914-21.

59. Jacquemin B, Siroux V, Sanchez M, et al. Ambient Air Pollution and Adult Asthma Incidence in Six European Cohorts (ESCAPE). Environ Health Perspect. 2015;123:613-21.

60. Ciencewicki J, Trivedi S, Kleeberger SR. Oxidants and the pathogenesis of lung diseases. J Allergy Clin Immunol. 2008;122:456-68; quiz 69-70.

61. Nel A. Atmosphere: Air Pollution-Related Illness: Effects of Particles. Science. 2005;308:804-6

62. Strak M, Janssen NA, Godri KJ, et al. Respiratory health effects of airborne particulate matter: The role of particle size, composition, and oxidative potential-the RAPTES project. Environ Health Perspect. 2012;120:1183-9.

63. Chuang HC, Fan CW, Chen KY, Chang-Chien GP, Chan CC. Vasoactive alteration and inflammation induced by polycyclic aromatic hydrocarbons and trace metals of vehicle exhaust particles. Toxicol Lett. 2012;214:131-6.

64. Becker S, Mundandhara S, Devlin RB, Madden M. Regulation of cytokine production in human alveolar macrophages and airway epithelial cells in response to ambient air pollution particles: further mechanistic studies. Toxicol Appl Pharmacol. 2005;207:269-75.

65. Siegel PD, Saxena RK, Saxena QB, et al. Effect of diesel exhaust particulate (DEP) on immune responses: contributions of particulate versus organic soluble components. J Toxicol Environ Health A. 2004;67:221-31.

66. Jerrett M, Arain A, Kanaroglou P, et al. review and evaluation of intraurban air pollution exposure models. J Expo Anal Environ Epidemiol. 2005;15:185-204.

67. Vienneau D, de Hoogh K, Bechle MJ, et al. Western European land use regression incorporating satellite- and ground-based measurements of $\mathrm{NO} 2$ and PM10. Environ Sci Technol. 2013;47:13555-64.

68. Brunekreef B, Dockery DW, Krzyzanowski M. Epidemiologic studies on short-term effects of low levels of major ambient air pollution components. Environ Health Perspect. 1995;103(Suppl 2):3-13.

69. Gotschi T, Sunyer J, Chinn S, et al. Air pollution and lung function in the European Community Respiratory Health Survey. Int J Epidemiol 2008;37:1349-58

70. Ackermann-Liebrich U, Leuenberger P, Schwartz J, et al. Lung function and long term exposure to air pollutants in Switzerland. Am J Respir Crit Care Med 1997;155:122-9

71. Downs SH, Schindler C, Liu LJ, et al. Reduced exposure to PM10 and attenuated age-related decline in lung function. N Engl J Med. 2007;357:2338-47.

72. Vawda S, Mansour R, Takeda A, et al. Associations between inflammatory and immune response genes and adverse respiratory outcomes following exposure to outdoor air pollution: a HuGE systematic review. Am J Epidemiol. 2014;179:432-42.

73. Bayer-Oglesby L, Grize L, Gassner M, et al. Decline of ambient air pollution levels and improved respiratory health in Swiss children. Environ Health Perspect. 2005;113:1632-7.

74. Adar SD, D'Souza J, Sheppard L, et al. Adopting Clean Fuels and Technologies on School Buses. Pollution and Health Impacts in Children. Am Respir Crit Care Med. 2015;191:1413-21.

75. Gauderman WJ, Urman R, Avol E, et al. Association of improved air quality with lung development in children. N Engl J Med. 2015;372:905-13. 